Genij Ortopedii. 2022. Vol. 28, no. 1. P. 62-68.

Original article

https://doi.org/10.18019/1028-4427-2022-28-1-62-68

\title{
Evaluation of the knee joint structures of pediatric patients with anterior cruciate ligament injury after conservative treatment
}

\author{
Yaroslav A. Ivanov ${ }^{\bowtie}$, Alexander G. Yeltsin, Dmitry S. Mininkov
}

National Medical Research Center of Traumatology and Orthopedics named after N.N. Priorov, Moscow, Russian Federation

Corresponding author: Yaroslav A. Ivanov, docyaroslav@gmail.com

\section{Abstract}

Background Conservative treatment of pediatric patients with anteromedial instability after ACL rupture is a very topical subject and raises many debates in the scientific community. Results of this treatment are rather controversial both in patients with open physis and in adult patients who reached skeletal maturity. Influence of anteromedial instability on damaging such structures of the knee joint and meniscus and articular cartilage also generates interest. Purpose The purpose is to evaluate results of conservative treatment in young athletes using methods of clinical examination, questionnaires and MRI-diagnostics. Material and methods The study included 20 patients with anteromedial instability aged 13-20 years. Duration of observation was up to 2.7 years (33 months). The patients filled out KOOS-Child and Pedi-IKDC questionnaires. At least two MRI-examinations were done also. The patients were treated conservatively. Results and discussion MRI data indicated that 9 (45\%) patients had osteochondral changes in condyles of the both bones. Thinning of the knee cartilage by $\geqslant 0.7 \mathrm{~cm}$ was observed in 14 patients. Eighteen patients has the clinically confirmed knee joint instability. Eight (40\%) patients underwent operative treatment later. Conclusion Our study results allowed us to make a conclusion about poor results of the conservative treatment. Only 2 patients returned to previous activities and the knee instability was not observed clinically. The rest of the patients were not satisfied with the treatment results. MRI data and statistical analysis data indicated that the patients had signs of significant weight distribution disorders in the knee joint and also secondary damage of meniscus due to anteromedial instability.

Keywords: children, knee joint, injury, secondary changes, meniscus damage, anteromedial instability, ACL injury, KOOS-Child; Pedi-IKDC; conservative treatment; evaluation of treatment results

Acknowledgments: The authors are grateful to Sergei Igorevich Moiseev for his great contribution to data analysis.

For citation: Ivanov Ya.A., Yeltsin A.G., Mininkov D.S. Evaluation of the knee joint structures of pediatric patients with anterior cruciate ligament injury after conservative treatment. Genij Ortopedii, 2022, vol. 28, no 1, pp. 62-68. https://doi.org/10.18019/1028-4427-202228-1-62-68

\section{INTRODUCTION}

Anteromedial instability of the knee joint associated with ACL rupture significantly increases the risk of developing secondary meniscal injuries [1-4], degenerative changes $[5,6]$ and, as a result, the likelihood of not returning to previous physical activity [7-11], and the quality of life also decreases $[12,13]$. All of the above problems are important arguments in favour of surgical treatment, which is recognized as the standard in patients of the adult age group. However, in paediatric patients, due to the active growth zone, a number of problems arise with the choice in favour of surgical treatment [14]. First of all, due to the risk of damage to the growth zones, which can lead to shortening of the limb and deformity of the knee joint [15-17]. There are also a number of difficulties associated with the technique of ACL repair in patients with active growth rates. Evaluation of the results of conservative treatment in the form of a clinical examination, questionnaires, as well as with the help of MRI studies of the structures of the knee joint makes it possible to improve understanding of this problem when looking at it from a broader angle.

\section{MATERIAL AND METHODS}

All patients and volunteers who took part in the clinical study gave their written consent for it. The stydy was conducted according to requirements of World Medical Association's Declaration of Helsinki (as revised in 2013). The study was approved by the Ethics Committee.

The following criteria for inclusion in the study were identified: ACL tear in patients aged 13 to 20 years. The patients were surveyed with the KOOS-Child and Pedi-IKDC questionnaires. A clinical examination was performed (Pivot-shift, Lachman tests). Also, at least two MRI studies were performed (the first weeks after the injury and at different times after the first study) using a device with a power of at least 1.5 Tesla. The average time between the $1^{\text {st }}$ and $2^{\text {nd }}$ MRI was 13 months, the minimum was 2 months, and the maximum was 33 months. In 14 people, MRI was performed on the same device. Study modes: T1, T2, PD, PD SW, T1 FSE. Patients were also prescribed conservative therapy, which included immobilization in an orthosis

(C) Ivanov Ya.A., Yeltsin A.G., Mininkov D.S., 2022 
for 4 weeks, a course of NSAIDs (non-steroidal antiinflammatory drugs) and subsequent rehabilitation.

The study was a single center. The study did not include patients who, in addition to ACL rupture, sustained fractures of the intercondylar eminence and damage to the lateral ligaments, LCL.

20 patients were selected for the study. They underwent conservative treatment for ACL rupture in the period from 2020 to 2021 . There were 12 male patients and 8 female patients. The follow-up period was up to 2.7 years (33 months).

To identify the interrelations between the criteria that determine the quality of treatment outcomes, methods of statistical analysis were used, including the theory of parametric and nonparametric correlation analysis. The goal was to identify the interrelations between the indicators, criteria and measuring instruments (MRI), which were used to assess the quality of patient care. The following tasks were solved: the choice of a measuring instrument for assessing the quality of treatment was substantiated; the adequacy of measurement methods, indicators and criteria used to measure treatment outcomes was assessed; quantitative interrelations between the criteria for assessing the quality of treatment were obtained; the structure of interchangeability and complementarity of methods of examination of patients and other tasks were determined.

\section{RESULTS}

According to MRI data, 10 (50\%) of 20 patients had osteochondral changes in the condyles of both bones; among them $8(40 \%)$ patients had changes on the lateral condyle of the femur, 1 patient had them on both condyles of the femur, and 1 patient had osteochondral changes on lateral condyles of the tibia and femur.

In the described case, an example of a sclerotic lesion of the bone marrow is shown. This "thickening" of the bone structure occurs due to improperly distributed load in the knee joint. The patient noted instability in the knee joint, which was confirmed by clinical examination and MRI data; ACL rupture was diagnosed. A constant local impact load is applied to the zone of sclerotic changes, as a result of which a compensatory response of the body occurs in the form of a thickening. Figure 1 shows images of the MRI studies 2 months apart.

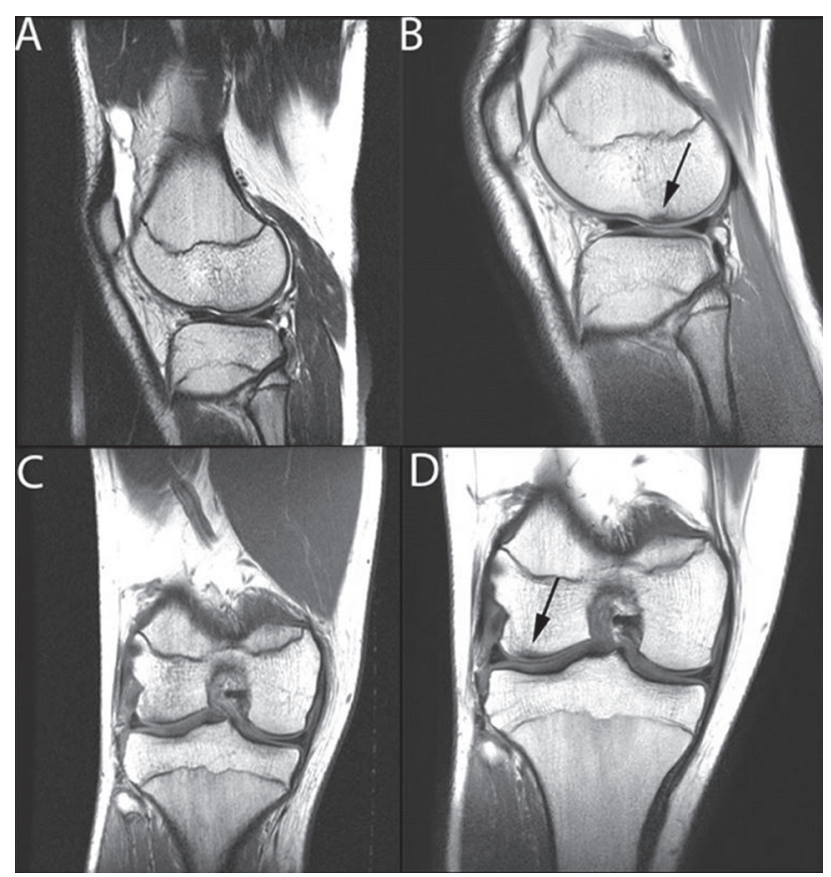

Fig. 1 Lateral part of the knee joint of the patient in the first weeks after trauma (A, C). 2 months later in the next MRI (mode PD TSE) in the same part there are (B, D) sclerotic changes of the bone tissue due to incorrect load distribution (black arrow)
Subsequently, the risk of transchondral fracture increases in the described zone, and cyst formation is possible [18]. Figure 2 shows MRI images of the knee joint 16 months apart.

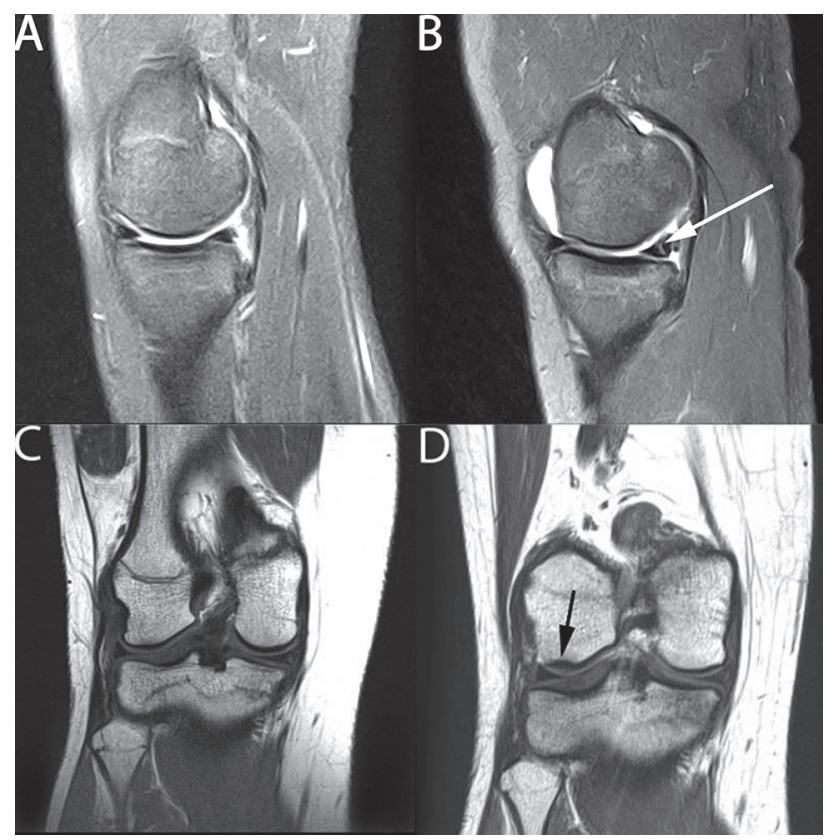

Fig. 2 Lateral part of the knee joint in the sagittal (A) and coronal (C) views. The study was done in the first week after the trauma. 16 months after the first MRI study (mode PD TSE FS (A, B) and mode T1 SE (C, D)) there is a damage (white arrow) of the posterior horn of the lateral meniscus (Stoller III) (B), and also sclerotic changes of the bone tissue (black arrow) due to incorrect load distribution in the knee joint secondary to anteromedial instability

The patient also complained about instability in the knee joint, which was confirmed clinically. Image (B) shows damage to the posterior horn of the lateral meniscus (Stoller IIIb) due to anteromedial instability of the knee after the ACL rupture. Also the patient, as in the first case (Fig. 1), had a sclerotic change in the bone structure of the lateral condyle of the femur, which is a confirmation of an incorrectly distributed load in the knee joint [19].

Figure 3 shows MRI images with a difference of 13 months between studies. The black arrow indicates 
the zone of starting destruction of the bone structure. This disorder is a consequence of the resulting transchondral fracture, which has undergone lytic influence of the synovial fluid.
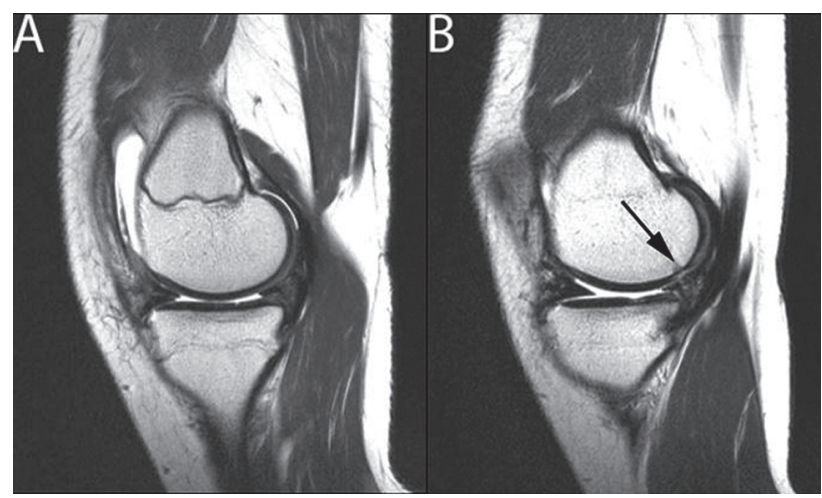

Fig. 3 MRI image (T1 SE mode) of the medial part of the knee joint (A) in the first weeks after injury, sagittal view. The same part of the knee joint 13 months after the first MRI (B). The image shows the beginning of bone tissue destruction as a result of the fracture (black arrow)

Figure 4 shows the data of the MRI study of the knee joint of a patient with an ACL rupture. Image (B) shows secondary damage to the posterior horn of the lateral meniscus (Stoller IIIb) due to anteromedial instability. In our study, 9 (45\%) patients were found to have meniscus injury: 5 patients had a rupture of the medial meniscus, and 4 patients had a rupture of the lateral meniscus.

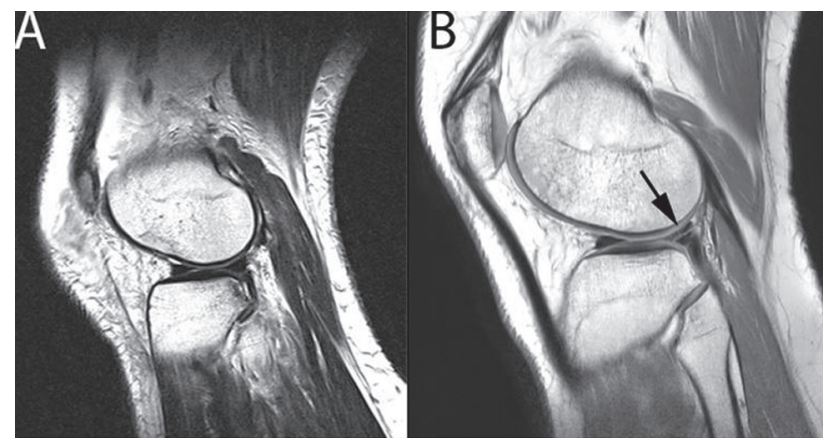

Fig. 4 MRI (T1 SE mode) of the knee joint in the sagittal view (A) in the first weeks after the injury. MRI (T1 SE mode) 5 months after the first examination (B). Damage to the posterior horn of the lateral meniscus is seen (black arrow)

Figure 5 shows a scheme for measuring cartilage thickness. Measurement is made in 2 projections: sagittal and coronal. On each condyle of the tibia and femur, three points are set at which the thickness of the cartilage is measured. There are 24 measurement points in total; after which a similar procedure is performed on the second MRI images of the patient, taken after a while. The measurement was performed using the RadiAnt software in T1, PDW, T2 modes. Currently, the most accurate method for measuring cartilage thickness is mapping. In our study, the measurement using this method was not performed. Due to the high probability of inaccuracy in conventional measurement using a ruler tool, an error of $0.7 \mathrm{~cm}$ was taken into account in the specialized software. According to the study data $4(20 \%)$ patients had thinning of the cartilage of the lateral condyle of the femur $\geq 0,7 \mathrm{~cm}, 2(10 \%)$ had thinning of both the lateral and medial femoral condyle $\geq 0.7 \mathrm{~cm}, 3(15 \%)$ had thinning of the cartilaginous coating only in the medial femoral condyle $\geq 0.7 \mathrm{~cm}$. In the lateral condyle of the tibia, thinning $\geq 0.7 \mathrm{~cm}$ was observed in $3(15 \%)$ patients, in both condyles $\geq 0.7 \mathrm{~cm}$ was observed in $6(30 \%)$ patients.

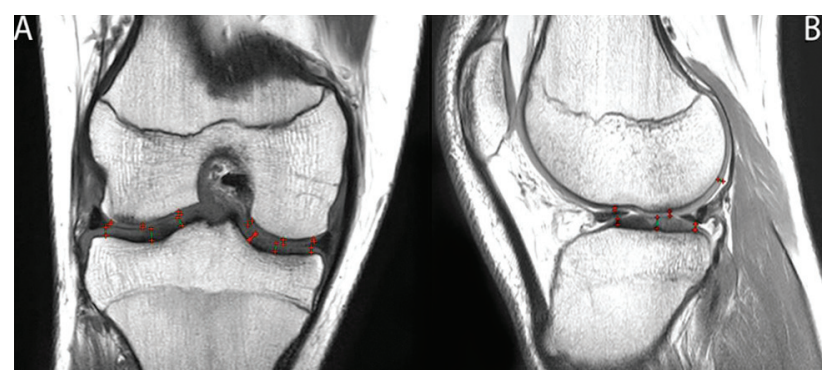

Fig. 5 The MRI-image (mode T1 SE) in the coronal view (A) shows the method for measuring the cartilage thickness at three points in every condyle of the tibia and the femur. In the sagittal view (B) there is an example of measuring cartilage thickness at three points in the medial condyles of the tibia and the femur.

Questionnaires KOOS-Child and Pedi-IKDC were used in the study in patients younger than 18 years; and questionnaires KOOS and IKDC - in older patients. The patients with complaints of instability in the knee joint were examined clinically. In 18 patients when doing tests of anterior "open box", Lachman and pivot-shift we observed instability. In addition to the indicated complaints the patients had to significantly decrease their activity or forgo sport completely. Only 2 patients out of 20 were satisfied with the results of conservative treatment and returned to previous activity. 8 (40\%) patients underwent surgical treatment later. It included ACL plasty in $6(30 \%)$ patients and resection of the injured part of the meniscus - in $2(10 \%)$ patients.

Revealing correlations between criteria determining quality of treatment results. Statistical analysis

This part has the goal of revealing correlations between indices, criteria and measuring instruments used for evaluation of treatment quality in anteromedial instability patients. Determining such correlations allows us to solve several tasks: to substantiate the choice of "measuring instrument" for evaluation of treatment quality; to judge about adequacy of the measuring methods, indices and criteria; to obtain quantitative interdependence between the criteria of treatment quality evaluation; to determine the structure of interchangeability and complementarity of the methods of examination.

The criteria of evaluation are shown in table 1 . This table also includes their symbolic representation, which will be used further on and also evaluation scale by criteria. 
Data of the criteria

\begin{tabular}{|c|l|c|}
\hline Symbol & \multicolumn{1}{|c|}{ Description } & Measuring scale \\
\hline K1 & Thickness of the cartilage of the lateral femoral condyle $(\mathrm{mm})$ & Numerical \\
\hline K2 & Thickness of the cartilage of the medial femoral condyle $(\mathrm{mm})$ & Numerical \\
\hline K3 & Thickness of the cartilage of the lateral tibial condyle $(\mathrm{mm})$ & Numerical \\
\hline K4 & Thickness of the cartilage of the medial tibial condyle $(\mathrm{mm})$ & Numerical \\
\hline K5 & Lateral meniscus & Dichotomous \\
\hline K6 & Medial meniscus & Dichotomous \\
\hline K7 & Osteochondral changes: lateral condyle of the femur & Dichotomous \\
\hline K8 & Osteochondral changes: medial condyle of the femur & Dichotomous \\
\hline K9 & Osteochondral changes: lateral condyle of the tibia & Dichotomous \\
\hline K10 & Doing MRI on the same device & Dichotomous \\
\hline K11 & Number of months between the MRI examinations & Numerical \\
\hline K12 & Age of the patient & Numerical \\
\hline K13 & KOOS-Child Pain & Numerical \\
\hline K14 & KOOS-Child Symptom & Numerical \\
\hline K15 & KOOS-Child ADL & Numerical \\
\hline K16 & KOOS-Child Sport/Rec & Numerical \\
\hline K17 & KOOS-Child QOL & Numerical \\
\hline K18 & Pedi-IKDC & Dichotomous \\
\hline K19 & Clinical tests of the knee joint instability & \\
\hline
\end{tabular}

At the first stage, it is necessary to determine the methods for calculating the correlation between the criteria in order to select a model for evaluating the interrelations between them. To this end it is necessary to statistically determine the possible law of the distribution of measurements for each criterion. Verification of the measurement distribution law for all criteria, carried out on the basis of chi-squared test [20-23], showed that evaluation by quantitative criteria are distributed according to a law close to normal, at a significance level not exceeding 0.05 . At the same time, the evaluation of the measurement results according to dichotomous criteria showed that the distribution differed from the normal one.

Based on this, it was decided to take as a basis nonparametric methods of correlation analysis (Spearman's rank correlation coefficient), which do not depend on the distribution law of the evaluated parameters, but to clarify the results for quantitative criteria, compare them with calculations using parametric methods built for the normal distribution law.

It is possible to calculate the boundary correlation coefficients for each gradation of interrelations after doing calculations with a sample size of $\mathrm{N}=20$.

- adaptive value $\left|r_{m n}\right|$ from 0.378 to 0.515 - moderate correlation;

- adaptive value $\left|r_{m n}\right|$ from 0.515 to 0.609 - strong correlation;

- adaptive value $\left|r_{m n}\right|$ from 0.609 to 1 - very strong correlation.

The figure 6 shows a scheme of correlations between the criteria. The disappearance of correlations in the diagram (B) suggests that the more powerful Pearson's criterion did not reveal a significant correlation between the indicated criteria, so these correlations may exist, but they should be taken into account with caution. On the other hand, Pearson's correlation revealed additional dependencies that Spearman's rank criterion did not determine, namely, new interrelations arose between the K4-K11, K6-K12, K13-K14 criteria. Taking into account the fact that K4-K11 and K13-K14 correlations show interrelations between numerical criteria that are distributed according to the normal law with high probability, there is a reason to believe that a more powerful evaluation method of Pearson correlation revealed an additional correlation between these criteria, which should be taken into account when analyzing correlations.

The following correlation were revealed as a result of the statistical analysis:

- very strong direct correlations were found between the thickness of the cartilaginous covering of the medial tibial condyle and the number of months between MRI scans; osteochondral changes in the medial condyle of the femur and the lateral condyle of the tibia; results of the KOOS-Child and Pedi-IKDC questionnaires;

- strong direct correlations were found between the thickness of the cartilage of the medial femoral condyle and osteochondral changes in the same condyle; medial meniscus and osteochondral changes in the medial condyle of the femur; 
- a very strong direct correlation was found between the results of the KOOS-Child, Pedi-IKDC tests and the lateral meniscus;

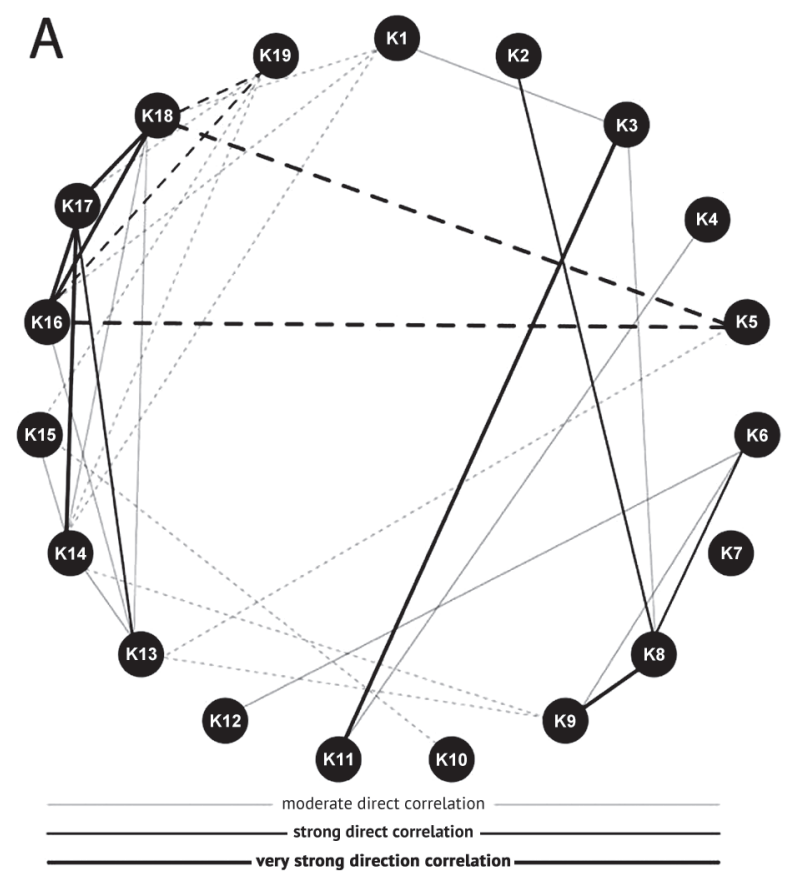

- a strong inverse correlation was found between the results of the KOOS-Child, Pedi-IKDC tests and the results of the clinical examination.

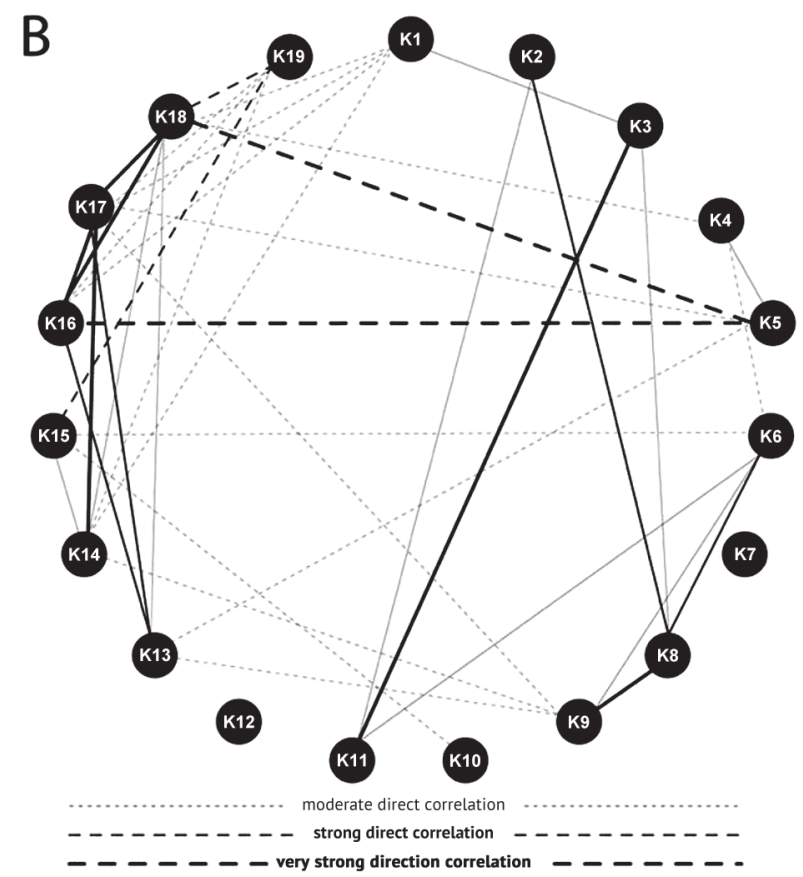

Fig. 6 Graphic representation of correlation between the criteria based on Spearman's rank correlation (A). Graphic representation of correlation between the criteria based on Pearson's parametric correlation (B)

\section{DISCUSSION}

Evaluation of the results of conservative treatment of pediatric patients with open physis is important. It The influence of anteromedial instability on structures of the knee joint is also interesting. Similar studies were also carried out abroad. Ekås G.R. et al. [24] examined the structure of the knee joint for the presence of pathologies associated with anteromedial instability after ACL rupture. The study involved 47 patients with a followup period of 9.5 years. The age of the patients was up to 13 years. The study included MRI of the both knee joints on a 3 Tesla device 1.2 and 9.5 years after the injury. 43 patients underwent conservative treatment, 4 patients underwent surgical treatment. According to the results of the study, 16 patients had meniscal injuries, 13 patients had articular cartilage injuries, 2 patients had a difference in limb length $>15 \mathrm{~mm}$. As a result, 27 patients $(57 \%)$ underwent ACL repair later. In conclusion, the authors report that in some cases, conservative treatment $(57 \%$ of patients without secondary changes in the knee joint and without signs of initial osteoarthritis) may be an option. Fabricant P.D. et al. [25] conducted a literature review to compare the results of conservative and surgical treatment in athletes younger than 18 years of age. In their review, Mizuta H. et al. presented a study [26], where $94 \%$ of 18 patients did not return to their previous physical activity, and $22 \%$ stopped doing sports at all after an ACL injury. Similar results were reported in the McCarroll study [27].
In our study, changes in osteochondral structures caused by anteromedial instability and incorrect load distribution in the knee joint were evaluated: sclerotic lesions of the bone marrow, beginning destruction of the bone structure, and signs of a transchondral fracture. In addition, cases of meniscus damage have been identified. Cartilage thickness was also measured, the thinning of which may indicate the formation of deforming arthrosis in the future. In our study, a high measurement error of cartilage thickness $(\geq 0.7 \mathrm{~cm})$ was taken, since the weakness in relation to the measurement is the lack of mapping in patients. Besides, even if the study is performed on the same device, the sections are set by the radiation diagnostician at the time of the study, which can also lead to inaccuracies in measuring the thickness of the cartilage. In this regard, in our study, osteochondral changes caused by anteromedial instability should be considered a more significant criterion of evaluation due to their objectivity. It is also important to consider the secondary meniscal injury due to the reason described above.

In addition to the use of MRI diagnostic data, the patients filled out questionnaires and a clinical examination was performed. Complaints of instability, clinically confirmed positive Lachman, PVN tests and low scores on the KOOS-Child and Pedi-IKDC questionnaires are of decisive importance 
in evaluation of long-term results of treatment, as well as the choice in favor of surgical stabilization of the knee joint.

Similar results were reported in other studies. Mizuta H. et al. [26] evaluated the results of conservative treatment in children with complete ACL rupture. The study involved 18 people with a follow-up period of at least 36 months. All patients filled out questionnaires using the Lysholm scale, where only one patient, who was able to return to the previous physical activity, had a good result. Re-injury to the menisci was observed in 6 patients. Radiological evidence of degenerative changes in the joint was observed in 11 patients. In conclusion, the author reported that the results of conservative treatment were unsatisfactory.
Moksnes H. et al. [28] studied the results of conservative treatment of patients at the age less than 12 years. The authors used their own algorithm as a method of conservative treatment. According to the results of the study, out of 46 people, 34 were not operated on, and $38 \%$ reduced their level of activity. The follow-up period was 2 years. Secondary meniscus injuries were observed in 8 people $(17 \%)$.

The work of Raad M. et al. [29] also raises interest. The authors observed a positive correlation between body mass index (BMI) and secondary meniscal injury in pediatric patients. Of the 160 patients, 143 were operated on later and 17 were treated conservatively. Perhaps this indicator can be taken into account in future works on the subject.

\section{CONCLUSION}

According to the results of the study, we conclude that the results of conservative treatment in young athletes are unsatisfactory. Only 2 patients returned to their previous physical activities, and on examination they had no signs of instability. In other cases, the patients were not satisfied with the results of treatment. Based on the data of MRI studies and statistical analysis data, patients had significant signs of disorders of load distribution in the knee joint, as well as secondary damage to the meniscus due to anteromedial instability of the knee joint. A correlation was also observed between the data of the clinical examination and the scores of the KOOS-
Child and Pedi-IKDC questionnaires, which indicated their informative value. When evaluating the results of treatment, we recommend using not only clinical examination data, but also asking the patients to fill out questionnaires, as well as performing MRI studies in order to search for signs indicating a manifestation of problems in the knee joint, which will give the most complete picture of its condition. However, our study is not without shortcomings that can be taken into account in the future work: participation in the study of a larger number of patients; using the method of articular cartilage mapping in order to obtain more accurate data and reduce measurement errors.

\section{REFERENCES}

1. Hagino T., Ochiai S., Senga S., Yamashita T., Wako M., Ando T., Haro H. Meniscal tears associated with anterior cruciate ligament injury. Arch. Orthop. Trauma Surg., 2015, vol. 135, no. 12, pp. 1701-1706. DOI: 10.1007/s00402-015-2309-4.

2. Hagmeijer M.H., Hevesi M., Desai V.S., Sanders T.L., Camp C.L., Hewett T.E., Stuart M.J., Saris D.B.F., Krych A.J. Secondary meniscal tears in patients with anterior cruciate ligament injury: relationship among operative management, osteoarthritis, and arthroplasty at 18 -year mean followup. Am. J. Sports Med., 2019, vol. 47, no. 7, pp. 1583-1590. DOI: 10.1177/0363546519844481.

3. Papastergiou S.G., Koukoulias N.E., Mikalef P., Ziogas E., Voulgaropoulos H. Meniscal tears in the ACL-deficient knee: correlation between meniscal tears and the timing of ACL reconstruction. Knee Surg. Sports Traumatol. Arthrosc., 2007, vol. 15, no. 12, pp. 1438-1444. DOI: 10.1007/s00167-007-0414-9.

4. Sanders T.L., Pareek A., Kremers H.M., Bryan A.J., Levy B.A., Stuart M.J., Dahm D.L., Krych A.J. Long-term follow-up of isolated ACL tears treated without ligament reconstruction. Knee Surg. Sports Traumatol. Arthrosc., 2017, vol. 25, no. 2, pp. 493-500. DOI: 10.1007/s00167-016-4172-4.

5. Spahn G., Schiltenwolf M., Hartmann B., Grifka J., Hofmann G.O., Klemm H.T. Das zeitabhängige Arthroserisiko nach vorderer Kreuzbandverletzung. Ergebnisse einer systematischen Literaturrecherche [The time-related risk for knee osteoarthritis after ACL injury. Results from a systematic review]. Orthopade, 2016, vol. 45, no. 1, pp. 81-90. (in German) DOI: 10.1007/s00132-015-3170-4.

6. Wang L.J., Zeng N., Yan Z.P., Li J.T., Ni G.X. Post-traumatic osteoarthritis following ACL injury. Arthritis Res. Ther., 2020 , vol. 22 , no 1, pp. 57. DOI: 10.1186/s13075-020-02156-5.

7. Fomin S., Gauffin H., Kvist J. Short-term recovery of physical activity and knee function after an acute knee injury. BMJ Open. Sport. Exerc. Med., 2020, vol. 6, no. 1, pp. e000950. DOI: 10.1136/bmjsem-2020-000950.

8. Geffroy L., Lefevre N., Thevenin-Lemoine C., Peyronnet A., Lakhal W., Fayard J.M., Chotel F.; French Arthroscopy Society. Return to sport and re-tears after anterior cruciate ligament reconstruction in children and adolescents. Orthop. Traumatol. Surg. Res., 2018, vol. 104, no. 8S, pp. S183-S188. DOI: 10.1016/j.otsr.2018.09.006.

9. Beck N.A., Lawrence J.T.R., Nordin J.D., DeFor T.A., Tompkins M. ACL tears in school-aged children and adolescents over 20 years. Pediatrics, 2017, vol. 139, no. 3, pp. e20161877. DOI: 10.1542/peds.2016-1877.

10. Kay J., Memon M., Marx R.G., Peterson D., Simunovic N., Ayeni O.R. Over 90 \% of children and adolescents return to sport after anterior cruciate ligament reconstruction: a systematic review and meta-analysis. Knee Surg. Sports. Traumatol. Arthrosc., 2018, vol. 26, no. 4, pp. 1019-1036. DOI: $10.1007 / \mathrm{s} 00167-018-4830-9$.

11. Dekker T.J., Godin J.A., Dale K.M., Garrett W.E., Taylor D.C., Riboh J.C. Return to sport after pediatric anterior cruciate ligament reconstruction and its effect on subsequent anterior cruciate ligament injury. J. Bone Joint Surg. Am., 2017, vol. 99, no. 11, pp. 897-904. DOI: 10.2106/JBJS.16.00758.

12. Filbay S.R. Early ACL reconstruction is required to prevent additional knee injury: a misconception not supported by high-quality evidence. Br. J. Sports Med., 2019, vol. 53, no. 8, pp. 459-461. DOI: 10.1136/bjsports-2018-099842.

13. Zayats V.V., Dulaev A.K., Dydykin A.V., Ulyanchenko I.N. Klinicheskaia effektivnost anatomicheskoi plastiki perednei krestoobraznoi sviazki kolennogo sustava [Clinical evaluation of anatomical reconstruction of the anterior cruciate ligament]. Genij Ortopedii, 2021, vol. 27, no. 1, pp. 4854. DOI: $10.18019 / 1028-4427-2021-27-1-48-54$ 
14. Sadykov R.Sh., Bogatov V.B., Ponamarev I.R. Plastika peredneŭ krestoobraznoĭ sviazki kolennogo sustava u deteĭ s otkrytymi zonami rosta [Plastic surgery of the anterior cruciate ligament of the knee joint in children with open growth zones]. Sbornik materialov Vserossiuskoi Nauchnoprakticheskoi Konferentsii, posviashchennō 75-letiiu professora A.P. Barabasha "Klassika i Innovatsii v Travmatologii i Ortopedii” [Proceedings of the All-Russian Scientific-Practical Conference dedicated to the 75th anniversary of Professor A.P. Barabash "Classics and Innovations in Traumatology and Orthopaedics"]. Saratov, Amirit, 2016, pp. 301-302. (in Russian)

15. Seil R., Weitz F., Menetrey J., Chotel F. Anatomical and technical considerations for pediatric ACL reconstruction. In: Nakamura N., Zaffagnini S., Marx R., Musahl V., editors. Controversies in the technical aspects of ACL reconstruction. Berlin, Heidelberg, Springer, 2017, chapter 48, pp. 61-71. DOI: 10.1007/978-3-662-52742-9_8.

16. Chotel F., Henry J., Seil R., Chouteau J., Moyen B., Bérard J. Growth disturbances without growth arrest after ACL reconstruction in children. Knee Surg. Sports Traumatol. Arthrosc., 2010, vol. 18, no. 11, pp. 1496-1500. DOI: 10.1007/s00167-010-1069-5.

17. Lawrence J.T., West R.L., Garrett W.E. Growth disturbance following ACL reconstruction with use of an epiphyseal femoral tunnel: a case report. J. Bone Joint. Surg. Am., 2011, vol. 93, no. 8, pp. e39. DOI: 10.2106/JBJS.J.00569.

18. Englund M., Guermazi A., Roemer F.W., Yang M., Zhang Y., Nevitt M.C., Lynch J.A., Lewis C.E., Torner J., Felson D.T. Meniscal pathology on MRI increases the risk for both incident and enlarging subchondral bone marrow lesions of the knee: the MOST Study. Ann. Rheum. Dis., 2010, vol. 69, no. 10, pp. 1796-1802. DOI: 10.1136/ard.2009.121681.

19. Roemer F.W., Frobell R., Hunter D.J., Crema M.D., Fischer W., Bohndorf K., Guermazi A. MRI-detected subchondral bone marrow signal alterations of the knee joint: terminology, imaging appearance, relevance and radiological differential diagnosis. Osteoarthritis Cartilage, 2009, vol. 17, no. 9, pp. 1115-1131. DOI: 10.1016/j.joca.2009.03.012.

20. Borovkov A.A. Matematicheskaia statistika: uchebnik [Mathematical statistics: textbook]. SPb., Lan, 2010,704 p. (in Russian)

21. Gevorkian P.S., Potemkin A.V., Eisymont I.M. Teoriia veroiatnostei i matematicheskaia statistika [Probability Theory and Mathematical Statistics]. M., Fizmatlit, 2016, 176 p. (in Russian)

22. Gmurman V.E. Teoriia veroiatnostei i matematicheskaia statistika: uchebnik dlia prikladnogo bakalavriata [Probability Theory and Mathematical Statistics: a textbook for the applied bachelor's level program]. Liubertsy, Iurait, 2016, 479 p. (in Russian)

23. Lloid E., Lederman U., editors. Spravochnik po prikladnoi statistike [Applied Statistics Handbook]. In 2 vol. M., Finansy i Statistika, 1990. (in Russian)

24. Ekås G.R., Laane M.M., Larmo A., Moksnes H., Grindem H., Risberg M.A., Engebretsen L. Knee pathology in young adults after pediatric anterior cruciate ligament injury: a prospective case series of 47 patients with a mean 9.5-year follow-up. Am. J. Sports Med., 2019, vol. 47, no. 7, pp. 15571566. DOI: $10.1177 / 0363546519837935$.

25. Fabricant P.D., Lakomkin N., Cruz A.I., Spitzer E., Marx R.G. ACL reconstruction in youth athletes results in an improved rate of return to athletic activity when compared with non-operative treatment: a systematic review of the literature. Journal of JISAKOS Joint Disorders \& Orthopaedic Sports Medicine, 2016, vol. 1, pp. 62-69. DOI: 10.1136/jisakos-2015-000013.

26. Mizuta H., Kubota K., Shiraishi M., Otsuka Y., Nagamoto N., Takagi K. The conservative treatment of complete tears of the anterior cruciate ligament in skeletally immature patients. J. Bone Joint. Surg. Br., 1995, vol. 77, no. 6, pp. 890-894. DOI: 10.1302/0301-620X.77B6.7593101.

27. McCarroll J.R., Rettig A.C., Shelbourne K.D. Anterior cruciate ligament injuries in the young athlete with open physes. Am. J. Sports Med., 1988, vol. 16, no. 1, pp. 44-47. DOI: 10.1177/036354658801600107.

28. Moksnes H., Engebretsen L., Eitzen I., Risberg M.A. Functional outcomes following a non-operative treatment algorithm for anterior cruciate ligament injuries in skeletally immature children 12 years and younger. A prospective cohort with 2 years follow-up. Br. J. Sports Med., 2013, vol. 47, no. 8, pp. 488-494. DOI: 10.1136/bjsports-2012-092066.

29. Raad M., Thevenin Lemoine C., Bérard E., Laumonerie P., Sales de Gauzy J., Accadbled F. Delayed reconstruction and high BMI z score increase the risk of meniscal tear in paediatric and adolescent anterior cruciate ligament injury. Knee Surg. Sports Traumatol. Arthrosc., 2019, vol. 27, no. 3, pp. 905-911. DOI: 10.1007/s00167-018-5201-2.

The article was submitted 19.04.2021; approved after reviewing 20.05.2021; accepted for publication 23.12.2021.

\section{Information about the authors:}

1. Yaroslav A. Ivanov - ORCID: 0000-0002-6352-2784, docyaroslav@gmail.com;

2. Alexander G. Yeltsin - Candidate of Medical Sciences, ORCID: 0000-0002-7736-9493, agyeltsin@gmail.com;

3. Dmitry S. Mininkov - Candidate of Medical Sciences, ORCID: 0000-0002-9490-6932, 45040311@mail.ru.

Source of funding The work was not funded.

Conflict of interest The authors declare absence of obvious and potential conflict of interest associated with the present publication.

Ethics review All the patients and their legal guardians gave their consent for participation in the study. 